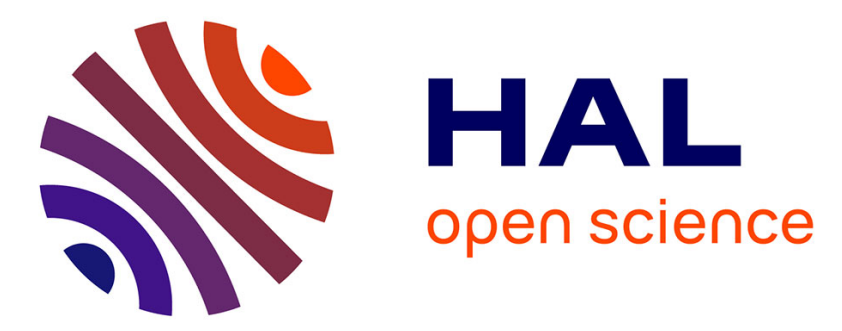

\title{
Influence of temperature on multicomponent diffusion in calcium and sodium aluminosilicate melts
}

Corinne Claireaux, Marie-Hélène Chopinet, Ekaterina Burov, Hervé

Montigaud, Mathieu Roskosz, Michael Toplis, Emmanuelle Gouillart

\section{- To cite this version:}

Corinne Claireaux, Marie-Hélène Chopinet, Ekaterina Burov, Hervé Montigaud, Mathieu Roskosz, et al.. Influence of temperature on multicomponent diffusion in calcium and sodium aluminosilicate melts. Journal of Non-Crystalline Solids, 2019, 505, pp.170-180. 10.1016/j.jnoncrysol.2018.09.046 . hal-02091791

\section{HAL Id: hal-02091791 \\ https://hal.science/hal-02091791}

Submitted on 6 Apr 2019

HAL is a multi-disciplinary open access archive for the deposit and dissemination of scientific research documents, whether they are published or not. The documents may come from teaching and research institutions in France or abroad, or from public or private research centers.
L'archive ouverte pluridisciplinaire HAL, est destinée au dépôt et à la diffusion de documents scientifiques de niveau recherche, publiés ou non, émanant des établissements d'enseignement et de recherche français ou étrangers, des laboratoires publics ou privés. 


\title{
Influence of temperature on multicomponent diffusion in calcium and sodium aluminosilicate melts
}

\author{
Corinne Claireaux ${ }^{\mathrm{a}}$, Marie-Hélène Chopinet ${ }^{\mathrm{a}}$, Ekaterina Burov ${ }^{\mathrm{a}}$, Hervé Montigaud $^{\mathrm{a}}$, Mathieu Roskosz ${ }^{\mathrm{b}}$, Michael J. \\ Toplis $^{\mathrm{c}}$, Emmanuelle Gouillart ${ }^{\mathrm{a}}$ \\ ${ }^{a}$ Surface du Verre et Interfaces (UMR 125), CNRS/Saint-Gobain Recherche, 39 quai Lucien Lefranc, 93300 Aubervilliers, France \\ ${ }^{b}$ Muséum National d'Histoire Naturelle, Institut de Minéralogie, de physique de la matière condensée et de cosmochimie, Sorbonne University, \\ Paris, France \\ ${ }^{c}$ Institut de Recherche en Astrophysique et Planétologie, Université de Toulouse, CNRS, UPS, CNES, Toulouse, France
}

\begin{abstract}
The effect of temperature on multicomponent chemical diffusion in liquids of the quaternary system $\mathrm{CaO}-\mathrm{Na}_{2} \mathrm{O}-\mathrm{Al}_{2} \mathrm{O}_{3}-\mathrm{SiO}_{2}$ has been studied. Diffusion-couple experiments were performed around a central composition of $64.5 \mathrm{wt} \% \mathrm{SiO}_{2}, 13.3 \mathrm{wt} \% \mathrm{Na}_{2} \mathrm{O}, 10.8 \mathrm{wt} \% \mathrm{CaO}, 11.4 \mathrm{wt} \% \mathrm{Al}_{2} \mathrm{O}_{3}$. Experiments were performed for three temperatures far above the glass transition $\left(1200,1280\right.$ and $1360^{\circ} \mathrm{C}$ ), as well as $30^{\circ} \mathrm{C}$ above the glass transition. Strong multidiffusive effects were observed for all temperatures, with significant uphill diffusion of calcium, demonstrating that uphill diffusion happens close to the glass transition as well as at high temperature. For each temperature, we determined the diffusion matrix of the system and quantified its eigenvectors and eigenvalues, which correspond formally to (respectively) exchanges between ions, and associated diffusion coefficients. Little variation of the eigenvectors of the diffusion matrix was observed as a function of temperature, with a dominant eigenvector corresponding to the exchange of sodium with calcium, the two other eigenvectors corresponding to the exchange of calcium with network formers. For the temperature range $1200-1360^{\circ} \mathrm{C}$, the eigenvalues of the diffusion matrix have an Arrhenian temperature dependence, with an activation energy consistent with electrical conductivity for the exchange of sodium and calcium, and an activation energy consistent with viscosity for eigenvectors involving network formers. Multicomponent diffusion close to the glass transition is characterized by the same eigenvectors as at higher temperature, but some diffusion profiles are asymmetric due to strong viscosity contrasts resulting in concentration-dependent eigenvalues. Moreover, we observe some departure from Eyring relation close to the glass transition, with diffusion eigenvalues several orders of magnitude greater than the Eyring prediction.
\end{abstract}

\section{Highlights}

- Multicomponent diffusion matrices were determined experimentally around a central composition of 64.5 $\mathrm{wt} \% \mathrm{SiO}_{2}, 13.3 \mathrm{wt} \% \mathrm{Na}_{2} \mathrm{O}, 10.8 \mathrm{wt} \% \mathrm{CaO}, 11.4 \mathrm{wt} \% \mathrm{Al}_{2} \mathrm{O}_{3}$, for three superliquidus temperatures and 30 degrees above the glass transition.

- Eigenvalues of the diffusion matrix were found to be Arrhenian down to 30 degrees above the glass transition.

- Eigenvalues of exchanges involving network formers are in good agreement with Eyring's law at superliquidus temperatures, but a departure from Eyring's law is observed close to the glass transition.

\section{Introduction}

Chemical diffusion is an essential transport mechanism in silicate and aluminosilicate melts and

Email address:

emmanuelle.gouillart@saint-gobain.com (Emmanuelle Gouillart)

Preprint
4 glasses (Zhang et al., 2010). In the glass industry as well as in magmatic processes, chemical diffusion at high temperature plays an important role for crystal nucleation and growth (Roskosz et al., 2005, 2006; Nascimento et al., 2004; Reinsch et al., 2008; Nascimento et al., 2011; Cassar et al., 2018), for mineral dissolution (Edwards and Russell, 1996; Liang, 1999; Acosta-Vigil et al., 2002, 2006; Chen and Zhang,

Preprint 
2008) and for phase separation (Mazurin and Streltsina, 1972; Bouttes et al., 2015). Closer to the glass tran14 sition, diffusion controls ionic exchanges for strength5 ened glasses (Smedskjaer et al., 2011; Vargheese et al., 2014), and exchanges between glass substrates and thin films (Fonné et al., 2017). In glasses, diffusion of alkali species is correlated with electrical conductivity (Jain et al., 1983; Natrup et al., 2005).

Since the mobility of elements is thermally activated, diffusion coefficients increase with temperature, typically following an Arrhenian law (Zhang et al., 2010). For network modifiers, crossing the glass transition does not affect the Arrhenian temperature dependency of self-diffusion coefficients (Jambon, 1982; Roselieb and Jambon, 1997, 2002). Activation energies for the different species can be significantly different, and are typically higher for network formers, particularly near the glass transition (Gruener et al., 2001).

However, the temperature dependency of multicomponent diffusion has been the focus of less attention (Liang, 2010). Multicomponent diffusion is a formalism which takes into account the cooperative nature of species mobility, using a diffusion matrix instead of scalar diffusivities. The diffusion matrix approach is necessary to account for phenomena such as uphill diffusion, in which a gradient of an initiallyconstant species arises because of couplings with other species. Diffusion coefficients are obtained as the eigenvalues of the diffusion matrix, while eigenvectors describe couplings between species, in the form of exchange reactions. Several studies in simplified systems (Chakraborty et al., 1995; Mungall et al., 1998; Liang and Davis, 2002; Liang, 2010) measured an Arrhenian temperature dependency of diffusion eigenvalues, and a global persistence of the direction of eigenvectors. This persistence was attributed to that of melt structure, since eigenvectors correspond to local configurational rearrangements. However, such studies were generally limited to ternary systems and concern measurements over relatively small temperature ranges at superliquidus conditions well above the glass transition. A recent exception in this latter respect is the study of multicomponent diffusion in a ternary borosilicate system (Pablo et al., 2017) that covers a temperature range of $400^{\circ} \mathrm{C}$ down to temperatures a little more than $100^{\circ} \mathrm{C}$ above the glass transition. In this case a degree of nonArrhenian behaviour was observed, but it was not possible to confirm whether diffusion and viscosity are correlated all the way down to $\mathrm{Tg}$.

In this work, we study the influence of temperature on multicomponent diffusion in the quaternary $\mathrm{CaO}-\mathrm{Na}_{2} \mathrm{O}-\mathrm{Al}_{2} \mathrm{O}_{3}-\mathrm{SiO}_{2}$ system, around a peralkaline
6412 composition. In (Claireaux et al., 2016), we previously 6513 determined the diffusion matrix at $1200^{\circ} \mathrm{C}$ for this system, and compared its eigenvectors to those of other systems in the literature. In this contribution, diffusioncouple experiments are used to determine the diffusion matrix over a very wide range of temperature, from superliquidus conditions $\left(1200,1280\right.$ and $\left.1360^{\circ} \mathrm{C}\right)$ down to $30^{\circ} \mathrm{C}$ above the glass transition (around $650^{\circ} \mathrm{C}$ ). Viscosity measurements are used to discuss the link between diffusivities computed from the diffusion matrix and viscosity at high temperature and close to the glass transition.

\section{Materials and methods}

\subsection{Glass compositions}

We study a composition domain centered on the peralkaline composition $\mathrm{C}_{0}=64.5 \mathrm{wt} \% \mathrm{SiO}_{2}$ , 13.3 wt $\% \mathrm{Na}_{2} \mathrm{O}, 10.8$ wt $\% \mathrm{CaO}, 11.4$ wt $\% \mathrm{Al}_{2} \mathrm{O}_{3}$ (corresponding to $\mathbf{C}_{0}=67.4 \mathrm{~mol} \% \mathrm{SiO}_{2}, \quad 13.5$ $\mathrm{mol} \% \mathrm{Na}_{2} \mathrm{O}, \quad 12.1 \mathrm{~mol} \% \mathrm{CaO}, 7.0 \mathrm{~mol} \% \mathrm{Al}_{2} \mathrm{O}_{3}$, or $\mathrm{Si}_{2.02} \mathrm{Na}_{1.62} \mathrm{Ca}_{0.73} \mathrm{Al}_{0.28} \mathrm{O}_{6}$ ). In (Claireaux et al., 2016), we studied multicomponent diffusion for this composition domain at $1200^{\circ} \mathrm{C}$.

We prepared a set of glasses centered on $\mathbf{C}_{0}$ for the diffusion-couple experiments. Choosing the concentration difference in a diffusion couple is a trade-off between two contradicting aspects: we expect the diffusion matrix to be independent of concentration only in a small domain, while increasing the signal to noise ratio of microprobe-analysis concentration profiles requires to have a larger initial step of concentration. Here we choose a maximal concentration difference of $5 \mathrm{wt} \%$. This concentration difference also ensures that all compositions lie in the peralkaline domain. We prepared 12 different glasses, each of them being enriched in one oxide and depleted in another with respect to $\mathbf{C}_{0}$. For example, we denote as AN a composition with $2.5 \mathrm{wt} \%$ more alumina, and $2.5 \mathrm{wt} \%$ less sodium oxide than $\mathbf{C}_{0}$.

Glasses were synthesized as described in (Claireaux et al., 2016). Compositions of the different glasses are given in Table 1 . We have also reported in Table 1 densities of the different compositions estimated at $1200^{\circ} \mathrm{C}$ using the models of (Bottinga et al., 1982), (Spera, 2000), (Priven, 2004) and (Fluegel et al., 2008). Values given in Table 1 correspond to the average of density values for the different models.

\subsection{Viscosities}

Viscosities of the 12 end-member compositions were measured in the range 1100 to $1400^{\circ} \mathrm{C}$, using a 


\begin{tabular}{l|ccccccccccccc} 
& $\mathbf{C}_{0}$ & AC & AN & AS & CA & CN & CS & NA & NC & NS & SA & SC & SN \\
\hline $\mathrm{Na}_{2} \mathrm{O}$ & 13.3 & 13.7 & $\mathbf{1 0 . 8}$ & 13.5 & 13.6 & $\mathbf{1 0 . 5}$ & 13.3 & $\mathbf{1 6 . 0}$ & $\mathbf{1 5 . 9}$ & $\mathbf{1 5 . 4}$ & 13.6 & 13.2 & 10.4 \\
$\mathrm{CaO}$ & 10.8 & $\mathbf{7 . 8}$ & 10.7 & 10.2 & $\mathbf{1 3 . 7}$ & $\mathbf{1 3 . 8}$ & $\mathbf{1 3 . 6}$ & 10.7 & $\mathbf{7 . 9}$ & 11.7 & 10.6 & $\mathbf{6 . 9}$ & 10.6 \\
$\mathrm{Al}_{2} \mathrm{O}_{3}$ & 11.4 & $\mathbf{1 3 . 4}$ & $\mathbf{1 3 . 3}$ & $\mathbf{1 3 . 5}$ & $\mathbf{8 . 4}$ & 12.0 & 11.4 & $\mathbf{8 . 9}$ & 11.6 & 10.8 & $\mathbf{8 . 9}$ & 11.7 & 11.7 \\
$\mathrm{SiO}_{2}$ & 64.5 & 65.1 & 65.4 & $\mathbf{6 2 . 1}$ & 64.3 & 63.6 & $\mathbf{6 1 . 7}$ & 64.3 & 64.6 & $\mathbf{6 2 . 0}$ & $\mathbf{6 6 . 9}$ & $\mathbf{6 6 . 7}$ & $\mathbf{6 6 . 8}$ \\
\hline density & & 2.35 & 2.38 & 2.37 & 2.36 & 2.40 & 2.40 & 2.37 & 2.35 & 2.38 & 2.36 & 2.34 & 2.37
\end{tabular}

Table 1: Compositions (in weight percents) and calculated densities $\left(\times 10^{3} \mathrm{~kg} \cdot \mathrm{m}^{-3}\right)$ of glasses used in diffusion couples. Chemical compositions were measured for each glass from the average of 20 electron microprobe analysis measurements. $\mathbf{C}_{0}$ is a theoretical composition (no glass of composition $\mathbf{C}_{0}$ was synthetized).

\begin{tabular}{l|cccccccccccc} 
& AC & AN & AS & CA & CN & CS & NA & NC & NS & SA & SC & SN \\
\hline$T_{g}$ (dilatometry) & 620 & 650 & 614 & 612 & 627 & 615 & 589 & 578 & 593 & 605 & 607 & 631 \\
$T_{g}\left(\eta=10^{12}\right.$ Pa.s) & 602 & 634 & 601 & 591 & 611 & 601 & 570 & 559 & 577 & 589 & 588 & 615
\end{tabular}

Table 2: Glass transition temperatures measured by dilatometry $\left(\log _{10} \eta(\mathrm{Pa} . \mathrm{s})=11.4\right)$, and extrapolated to $\log _{10} \eta=12$ using the VFT model determined from the high and low-temperature viscosity measurements.

home-made Couette rheometer and samples of 100-g. 14412 formation of cracks during quenching.

Low-temperature viscosity values were obtained from

dilatometry measurements. For dilatometry, 5x5×25 $\mathrm{mm}^{3}$ samples were heated at $5^{\circ} / \mathrm{min}$ in a Netzsch Power unit apparatus. The relative evolution of the length of the glass slab gives access to the dilatometric glass temperature (corresponding to $\left.\log _{10} \eta(\mathrm{Pa} . \mathrm{s})=11.4\right)$ and to the dilatometric softening point (corresponding to $\log _{10} \eta$ (Pa.s) = 9.4). For DSC measurements, samples were subjected to a $10^{\circ} / \mathrm{min}$ heating ramp in a Multi HTC 96 Setaram calorimeter. The glass transition was determined as the intersection between baseline and peak tangents. DSC glass transition temperatures are consistently $20^{\circ} \mathrm{C}$ higher than dilatometric glass transition temperatures, probably because of the faster heating ramp (Toplis et al., 2001). Therefore, dilatometry was preferred to DSC to determine the glass transition temperatures. Glass transition temperatures are given for the 12 endmembers in Table 2 for the dilatometric values $\left(\log _{10} \eta\right.$ (Pa.s) $\left.=11.4\right)$, and for the extrapolation to $\log _{10} \eta=12$ calculated using a VFT model obtained from fitting high-temperature and dilatometric measurements (see below).

\subsection{Diffusion experiments}

Square slabs of dimensions $15 \times 15 \times 5 \mathrm{~mm}^{3}$ of the different glasses were cut. Each slab was polished to ensure a good contact between the two slabs, limiting the formation of bubbles. Slabs were placed in vitreous silica crucibles of 25-mm diameter, the denser glass being placed below the lighter one. The space between the crucible and the glass slabs was filled with quartz sand to limit slumping of the melt, and to mitigate the
113 Three temperatures above the liquidus of $\mathbf{C}_{0}$ were selected: 1200,1280 and $1360^{\circ} \mathrm{C}$. Diffusion experiments were attempted outside this temperature range, but results could not be exploited because of crystallization below $1200^{\circ} \mathrm{C}$, and systematic convection above $1360^{\circ}$.

In order to investigate multicomponent diffusion close to the glass transition, we first measured the glass transition temperatures for the 12 compositions using dilatometry and differential scanning calorimetry (DSC).

For a given diffusion couple (e.g. AN/NA), the annealing temperature was chosen as approximately $30^{\circ}$ $\mathrm{C}$ above the higher of the two glass transition temperatures (corresponding to $\eta=10^{12} \mathrm{~Pa} . \mathrm{s}$ ), to ensure that a significant displacement of network formers can be observed across the whole sample. Annealing temperatures are reported in Table 3 for the different diffusion couples. For the experiments close to $T_{g}$, glass slabs were polished to optical quality before being put in contact, in order to ensure a good contact between the two slabs.

Crucibles were introduced into an electric furnace preheated at the temperature of interest. A thermocouple placed close to the crucible indicated that samples reached the temperature of interest a few minutes after being put inside the furnace. This time was defined as $t=0$. Counting from this point, isothermal treatments of durations of 20 minutes, 1 hour and 3 hours were performed for all diffusion couples at $1200^{\circ} \mathrm{C}$, of 20 minutes and 1 hour at $1280^{\circ} \mathrm{C}$, and of 20 minutes at $1360^{\circ}$. Samples were then quenched in air and annealed at $600^{\circ} \mathrm{C}$ for one hour to avoid fracture during sub- 


\begin{tabular}{r|cccccc} 
& AC/CA & AN/NA & NC/CN & SA/AS & SC/CS & SN/NS \\
\hline temperature $\left({ }^{\circ} \mathrm{C}\right)$ & 652 & 683 & 657 & 647 & 647 & 657 \\
$\mathrm{t}$ (days) & 40 & 47 & 45 & 35 & 35 & 41
\end{tabular}

Table 3: Temperatures and durations of thermal treatments close to the glass transition for the different diffusion couples. Temperatures were chosen as 30 degrees above the highest glass transition of the two endmembers.

sequent sample preparation. They were then mounted in epoxy resin, cut perpendicularly to the interface, and polished to optical quality for further observation. For annealing close to the glass transition, annealing durations are found in Table 3. At the end of the thermal treatment samples were quenched in air.

\subsection{Diffusion profiles}

The absence of convection was assessed using optical microscopy (using color contrast thanks to $100 \mathrm{ppm}$ of cobalt oxide added to one of the endmembers) as well as scanning electron microscopy in back-scattered mode, on a Zeiss Gemini DSM 982 FEG-SEM. A fraction of the experiments had to be discarded because of convection, especially at 1280 and $1360^{\circ} \mathrm{C}$.

Diffusion profiles of high-temperature experiments were measured using a Cameca SX-100 electron microprobe at the University of Lille. Analyses were performed for 20 seconds with an acceleration voltage of $15 \mathrm{kV}$, a current of $15 \mathrm{nA}$ and a spot size of 20 microns in order to reduce the charge density on the sample. For an accurate measurement of sodium concentration, four counting intervals of 5 seconds were used, and a regression performed to extrapolate decreasing concentrations back to the initial concentration. Measurement accuracy on sodium oxide is of the order of $1 \mathrm{wt} \%$, while that of the other elements is of the order of $0.2 \mathrm{wt} \%$. Along a diffusion profile, two measurement points were always separated by at least 30 microns to limit the impact of sodium migration at one point on adjacent measurements. For the low temperature diffusion experiments, the composition profiles were acquired using a Cameca SXFive electron microprobe at Saint-Gobain Research Paris. An improved methodology has been developed in order to reduce the distance step without any artefact on the results especially concerning the sodium concentration. The acquisitions were performed at $15 \mathrm{kV}$ with a beam current of $10 \mathrm{nA}$ during $10 \mathrm{~s}$ for $\mathrm{Na}-\mathrm{Ka}, \mathrm{Al}-\mathrm{Ka}$, $\mathrm{Si}-\mathrm{Ka}$ and $\mathrm{Ca}-\mathrm{Ka}$ peaks and their corresponding background. The analyzed area was a rectangle of $40 \times 2$ $\mu \mathrm{m}$ which large side was oriented parallel to the interface between the two glasses. The distance between each rectangle was fixed at $4 \mu \mathrm{m}$. A second series of analyses has been performed on a parallel profile separated from $50 \mu \mathrm{m}$. The steps of the second profile were
177 shifted by $3 \mu \mathrm{m}$ compared to the first one. Considering that the composition of the glass is homogeneous in the direction parallel to the interface over at least 100 $\mu \mathrm{m}$, merging (intertwining) the two line scans leads to a composition profile with a $3 \mu \mathrm{m}$ step. The accuracy of the composition (in $\mathrm{wt} \%$ ) is estimated at $\pm 0.4 \mathrm{wt} \%$ for $\mathrm{Na}_{2} \mathrm{O}, \pm 0.3 \mathrm{wt} \%$ for $\mathrm{CaO}$ et $\mathrm{Al}_{2} \mathrm{O}_{3}$ and $\pm 0.7 \mathrm{wt} \%$ for $\mathrm{SiO}_{2}$. The lack of impact of this protocol on the sodium composition was tested (and validated) far from the interface on an homogeneous zone.

\subsection{Mathematical analysis of diffusion profiles}

For each temperature, the diffusion matrix was obtained from the least-square minimization of the difference between theoretical and experimental diffusion profiles. Details about the theoretical background of the diffusion matrix and the numerical procedure can be found in (Claireaux et al., 2016). Briefly, the leastsquare error was computed in the eigenbasis of the diffusion matrix, with the theoretical diffusion profiles given by

$$
\tilde{C}_{i}(x, t)=\Delta \tilde{C}_{i} \operatorname{erf}\left(\frac{x}{\sqrt{2 \alpha_{i} t}}\right) .
$$

where $\alpha_{i}$ is an eigenvalue of the diffusion matrix and $\tilde{C}_{i}(x, t)$ is the projection of the concentration profiles of the different species, along the direction of the eigenvector $i$.

\section{Results}

\subsection{Viscosities}

Experimental viscosity values are shown in Fig. 1 for all end-member compositions. Compositions enriched in network formers have a larger viscosity than compositions with more sodium or calcium, with a slightly more important effect of aluminum compared to silicon. The greatest viscosity variations at fixed temperature are thus for the couple AN-NA. At $1200^{\circ} \mathrm{C}$, there is a ratio of 6 between $\eta(\mathrm{AN})$ and $\eta(\mathrm{NA})$, while at $T_{g}+30$, the viscosity ratio for this diffusion couple is greater than 100.

We obtained activation energies between 210 and $260 \mathrm{~kJ} \cdot \mathrm{mol}^{-1}$ when fitting viscosity values in the range $[1000-1450]^{\circ} \mathrm{C}$ with an Arrhenian law. For the 


\begin{tabular}{r|r|cccccc} 
temperature & duration & AC/CA & AN/NA & NC/CN & SA/AS & SC/CS & SN/NS \\
\hline$T_{g}$ & see Tab. 3 & $\checkmark$ & $\checkmark$ & $\checkmark$ & $\checkmark$ & $\checkmark$ & $\checkmark$ \\
\hline $1200^{\circ} \mathrm{C}$ & $20 \mathrm{~min}$ & $\checkmark$ & $\checkmark$ & $\checkmark$ & $\checkmark$ & $\checkmark$ & $\checkmark$ \\
& $1 \mathrm{~h}$ & $\checkmark$ & $\checkmark$ & $\checkmark$ & $\checkmark$ & $\checkmark$ & $\checkmark$ \\
& $3 \mathrm{~h}$ & $\checkmark$ & $\checkmark$ & conv. & $\checkmark$ & crystal. & $\checkmark$ \\
\hline $1280^{\circ} \mathrm{C}$ & $20 \mathrm{~min}$ & $\checkmark$ & conv. & $\checkmark$ & $\checkmark$ & crystal. & $\checkmark$ \\
& $1 \mathrm{~h}$ & conv. & conv. & conv. & $\checkmark$ & $\checkmark$ & conv. \\
\hline $1360^{\circ} \mathrm{C}$ & 20 min & conv. & conv. & $\checkmark$ & $\checkmark$ & $\checkmark$ & $\checkmark$
\end{tabular}

Table 4: Diffusion experiments. While most experiments were successful, part of the results could not be used due to convection (conv.) or crystallization at the interface (crystal.).
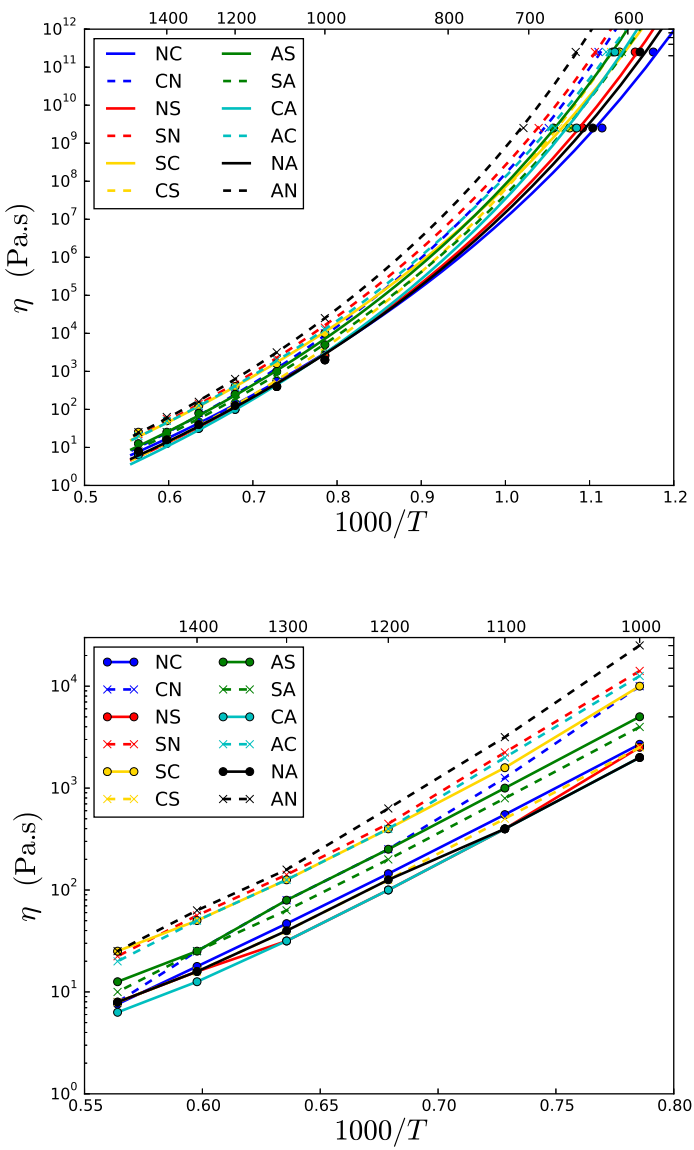

Figure 1: Viscosity of end-member melts. (Top) All measurements, obtained with DSC, dilatometry and viscometry analyses. Experimental points (symbols) are fitted with a Vogel-Fulcher-Tammann law. (Bottom) Zoom on high-temperature measurements, obtained from rotating-cylinder viscometry. whole temperature range, we fitted both the hightemperature and dilatometric measurements using the Vogel-Fulcher-Tammann (VFT) equation

$$
\log \eta=A+\frac{B}{T(K)-C}
$$

\subsection{Diffusion profiles}

For diffusion couples and temperatures at which several heating times were available, we first verified that diffusion profiles were similar when rescaled by $x / \sqrt{t}$ (see for example Fig. 3 of (Claireaux et al., 2016)). Consequently, diffusion profiles are shown in the following as a function of $x / \sqrt{t}$, in Figs. 2, 3, 4 and 5 for 1200, $1280,1360^{\circ} \mathrm{C}$ and $T_{g}+30$ respectively. For the sake of clarity, concentration profiles are represented as the difference between local and average concentration. For all temperatures, note that the spatial resolution is sufficient to have several measurement points in regions of high variation for all oxides, confirming that heat treatments were long enough even close to the glass transition.

Diffusion profiles at the three high temperatures are qualitatively very similar, except for the fact that diffusion widths increase with temperature for a given annealing time. As an example, the concentration profiles at $1200^{\circ} \mathrm{C}$ are described. Experiments with an initial difference of sodium oxide show a larger diffusion width than experiments with the same concentration of sodium oxide for the two end-members. The most significant uphill diffusion is the one of calcium, in the case of exchanges between sodium and network formers (NA/AN and NS/SN couples). Uphill diffusion of calcium is also observed for the AS/SA couple, for which there exists a small concentration difference in sodium oxide between end members. Minor uphill diffusion of aluminum is also observed for the SC/CS, NS/SN and $\mathrm{SA} / \mathrm{AS}$ couples, although these are at the limit of detection given the signal to noise ratio. Network formers have diffusion widths much smaller than that of sodium, 
while the characteristic length scale of sodium diffusion is approximately the same for all experiments. Calcium, however, has a larger diffusion width when it diffuses against sodium than when it diffuses against a network former. Finally, we note a slight asymmetry of sodium profiles for the NA-AN couple.

Interestingly, diffusion profiles close to the glass transition also share the same features as at high temperature, with uphill diffusion of calcium when sodium diffuses against network formers, and a much larger diffusion distance of network modifiers than those of network formers. Compared to the high temperatures, the most striking difference is the stronger asymmetry of diffusion profiles, in particular for sodium and calcium. A close-up visualization of the asymmetry is given in Fig. 6 for sodium profiles, where we have compared experimental sodium profiles to the symmetrized profiles

$$
c_{\text {sym }}(x)=\frac{1}{2}(c(x)-c(-x)) .
$$

A discontinuity of the sodium profile is even observed at the interface for the NA-AN couple (see Fig. 5). Experiments with a gradient of aluminum show a slight uphill diffusion of sodium. Uphill diffusion of sodium is only observed close to $T_{g}$ and not at higher temperature.

\subsection{Diffusion matrix}

For each temperature of the $[1200-1360]^{\circ} \mathrm{C}$ range, we used all available diffusion couples to obtain the least-square estimation of the diffusion matrix. Close to $T_{g}$, the AN/NA couple was not used for the estimation of the diffusion matrix, since the annealing temperature was significantly different from the other experiments and the asymmetry of the profiles is very strong. Note that for each temperature, the number of experiments used for the estimation is greater or equal than the minimal number (3) of experiments needed to cover enough directions in the composition space in order to determine the diffusion matrix (Trial and Spera, 1994; Liang, 2010).

Quality of the fits. Theoretical diffusion profiles obtained with the best-fit diffusion matrix are superimposed on experimental data in Figs. 2-5. The agreement between theoretical and experimental data is very good for the high temperatures. Close to the glass transition, asymmetries of the diffusion profiles are not taken into account into the model of constant diffusion matrix, hence the agreement is not as good for asymmetric profiles.
Diffusion matrices. Diffusion matrices obtained from the fits are shown in Table 5 with $\mathrm{SiO}_{2}$ as a dependent component, and in Table 6 as sets of eigenvalues and eigenvectors. The latter form has two advantages: first, no dependent component is needed and all oxides are treated symmetrically, and second, the interpretation of eigenvalues (as diffusion coefficients) and eigenvectors (as exchange directions) is easier. In Table 6 eigenvectors and eigenvalues are sorted by decreasing eigenvalue, that is from the fastest to the slowest diffusion mechanism. Errors estimations given in Tables 5 and 6 were computed generating several (200) realizations of synthetic diffusion profiles, using the estimated matrix and adding Gaussian noise of the same intensity as experimental noise, fitting the diffusion matrix on these synthetic profiles, and computing the standard deviation of coefficients.

Eigenvectors. The dominant eigenvector is the same for all temperatures. It consists in the exchange of sodium and calcium (see Table 6), so that the diffusion couple $\mathrm{NC} / \mathrm{CN}$ corresponds to the direction of the dominant eigenvector. Such exchange occurs probably through a "hopping" mechanisms in network modifiers channels (Jund et al., 2001; Meyer et al., 2004; Tilocca, 2010). Microscopic models explaining fast ionic conduction (such as the $\mathrm{Na}-\mathrm{Ca}$ exchange observed here) have been proposed in the literature, with for example the bond fluctuation model of ionic conduction (Aniya, 1992; Hull, 2004). The second eigenvector is characterised by the exchange of calcium with silicon, associated with a smaller fraction of aluminum. The relative proportion of silicon and aluminum varies with temperature, such that close to $T_{g}$, no aluminum is involved in the exchange reaction. The last eigenvector corresponds to the exchange of aluminum with calcium, and a smaller proportion of silicon. Close to $T_{g}$ this reaction boils down to the exchange of calcium and aluminum. For all temperatures the angle between a pair of eigenvector is of the order of $60^{\circ}$, corresponding to a normalized scalar product of $1 / 2$, in-between the normalized scalar product of orthogonal vectors (0) and of colinear vectors (1).

Eigenvalues. At each temperature, the largest eigenvalue is much larger than the other two. The ratio between the largest and second eigenvalue decreases with temperature, from 118 close to $T_{g}$ to 33 at $1360^{\circ} \mathrm{C}$. Such large ratios mean that diffusion matrices are illconditioned, which reduces the accuracy with which eigenvalues and eigenvectors are determined. 
$\bullet \mathrm{Na}_{2} \mathrm{O} \square \mathrm{CaO} \diamond \mathrm{Al}_{2} \mathrm{O}_{3}$

Experiments at $1200^{\circ} \mathrm{C}$
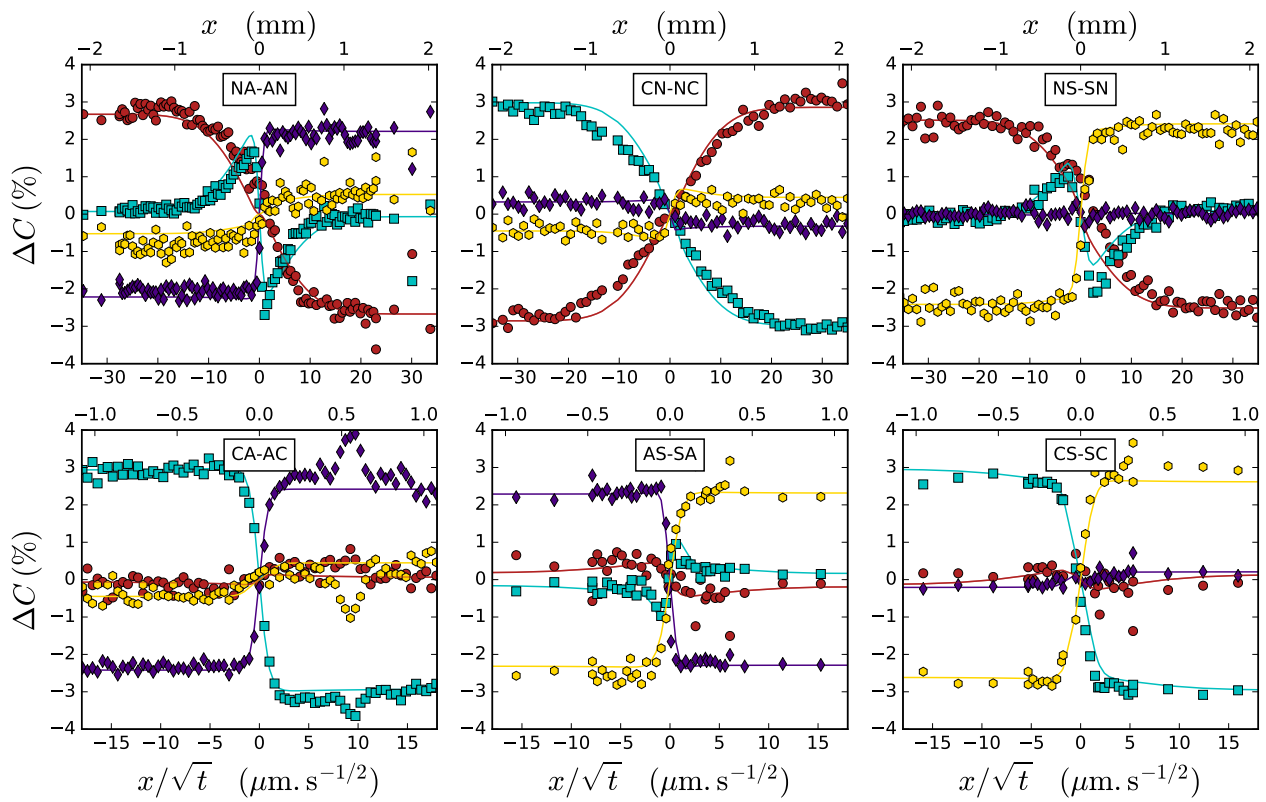

Figure 2: Concentration profiles for all diffusion couples at $1200^{\circ} \mathrm{C}$ and 1-hour treatments. Note the different spatial scale for diffusion couples involving sodium (first line) and not involving sodium (second line). Spatial coordinates are given both in mm and in rescaled units.

$$
\bullet \mathrm{Na}_{2} \mathrm{O} \square \mathrm{CaO} \diamond \mathrm{Al}_{2} \mathrm{O}_{3}
$$
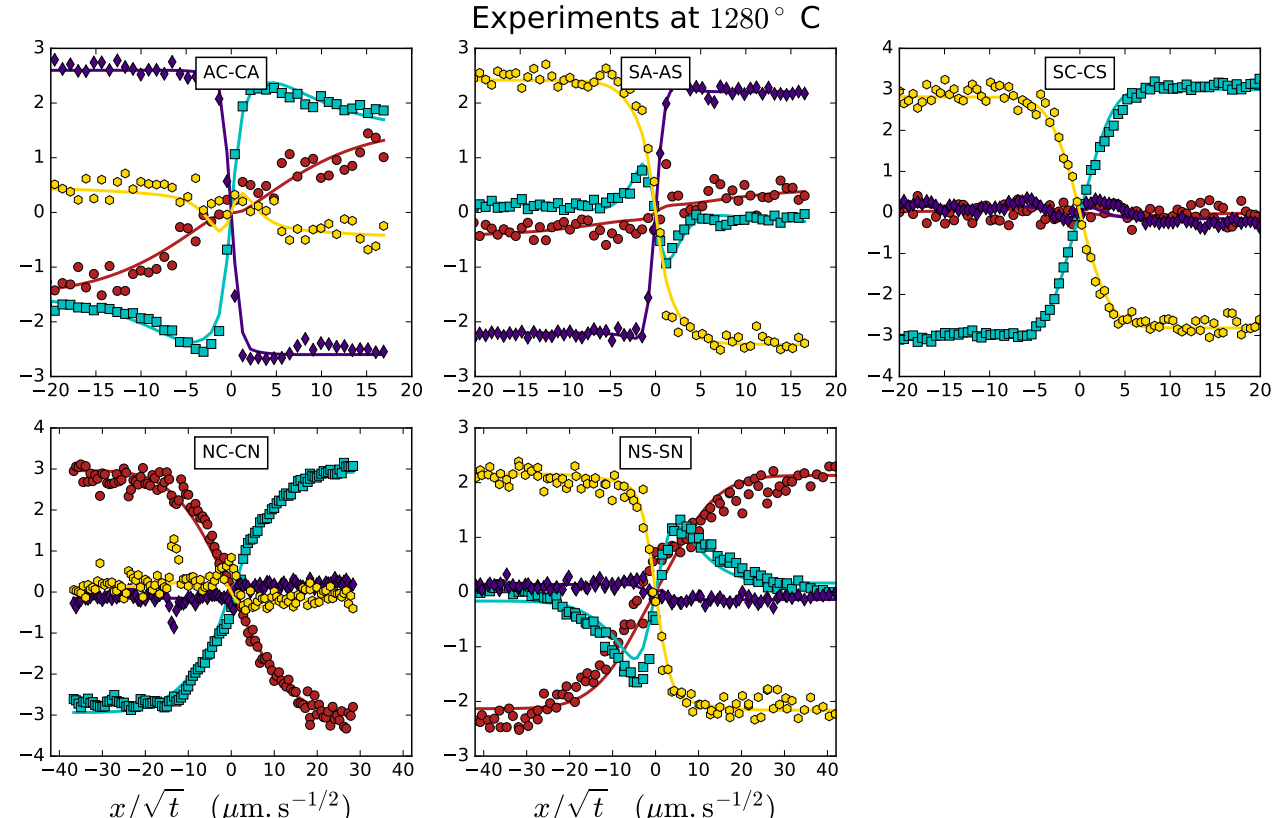

Figure 3: Concentration profiles for all successful diffusion couples at $1280^{\circ} \mathrm{C}$, corresponding to thermal treatments of 20 min for AC-CA, NC-CN and NS-SN couples and 1 hour for the SA-AS and SC-CS couples. 


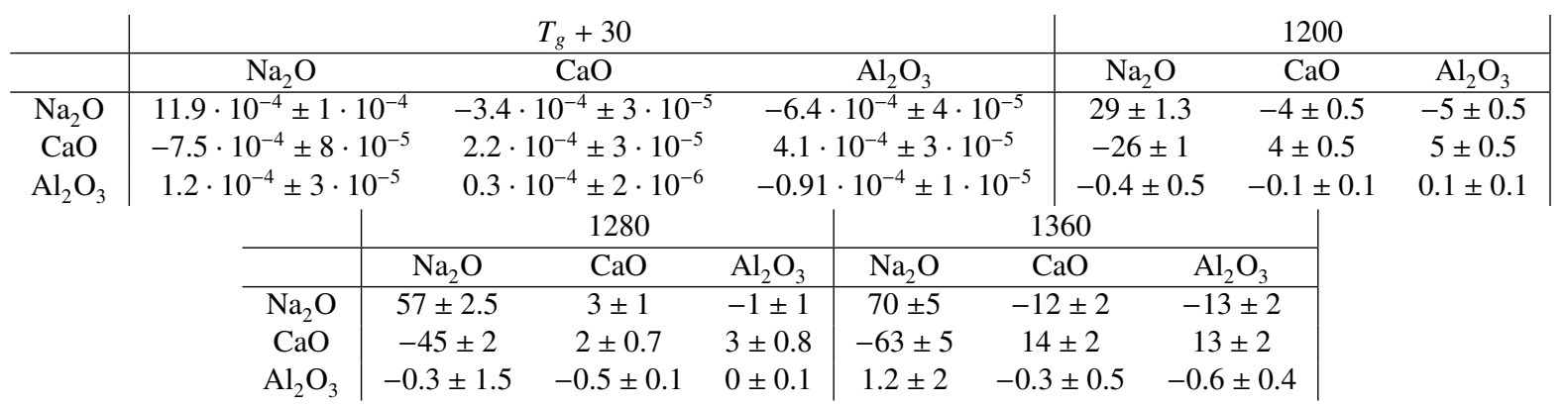

Table 5: Diffusion matrices obtained with $\mathrm{SiO}_{2}$ as dependent component. Coefficients are given in $\times 10^{-12} \mathrm{~m}^{2} . \mathrm{s}^{-1}$.

\begin{tabular}{c|ccc|ccc|ccc|ccc} 
& \multicolumn{3}{|c|}{$T_{g}+30$} & \multicolumn{3}{c}{1200} & \multicolumn{3}{c|}{1280} & \multicolumn{3}{c}{1360} \\
\hline$\alpha_{i}$ & $2.0 \cdot 10^{-3}$ & $1.7 \cdot 10^{-5}$ & $6.6 \cdot 10^{-7}$ & 29.5 & 0.58 & 0.3 & 59.1 & 2.01 & 0.32 & 133 & 4.1 & 0.62 \\
& $\pm 9.10^{-5}$ & $\pm 3.10^{-6}$ & $\pm 4.10^{-7}$ & \pm 1.5 & \pm 0.1 & \pm 0.05 & \pm 3 & \pm 0.3 & \pm 0.05 & \pm 4 & \pm 0.4 & \pm 0.15 \\
\hline $\mathrm{Na}_{2} \mathrm{O}$ & 1 & 0.06 & -0.19 & 1 & 0.07 & -0.08 & 1 & -0.05 & -0.05 & 1 & 0.11 & -0.09 \\
$\mathrm{CaO}$ & -0.84 & 0.94 & 1 & -0.91 & 1 & 0.74 & -0.84 & 1 & 0.70 & -0.94 & 1 & 0.55 \\
$\mathrm{Al}_{2} \mathrm{O}_{3}$ & 0.02 & 0 & -0.91 & -0.01 & -0.34 & -1 & 0.00 & -0.15 & -1 & 0.02 & -0.36 & -1 \\
$\mathrm{SiO}_{2}$ & -0.14 & -1 & 0.09 & -0.08 & -0.73 & 0.34 & -0.16 & -0.80 & 0.35 & -0.07 & -0.75 & 0.54
\end{tabular}

Table 6: Eigenvalues $\left(\times 10^{-12} \mathrm{~m}^{2} \cdot \mathrm{s}^{-1}\right)$ and eigenvectors obtained by fitting experimental data separately for each temperature.

$\bullet \mathrm{Na}_{2} \mathrm{O} \quad \mathrm{CaO} \quad \mathrm{Al}_{2} \mathrm{O}_{3}$

Experiments at $1360^{\circ} \mathrm{C}$
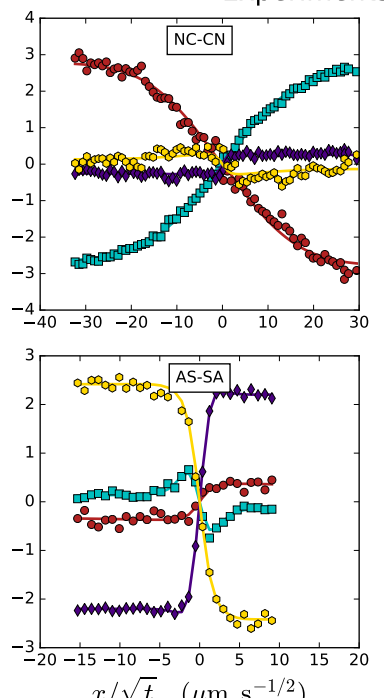

$x / \sqrt{t}\left(\mu \mathrm{m} \cdot \mathrm{s}^{-1 / 2}\right)$
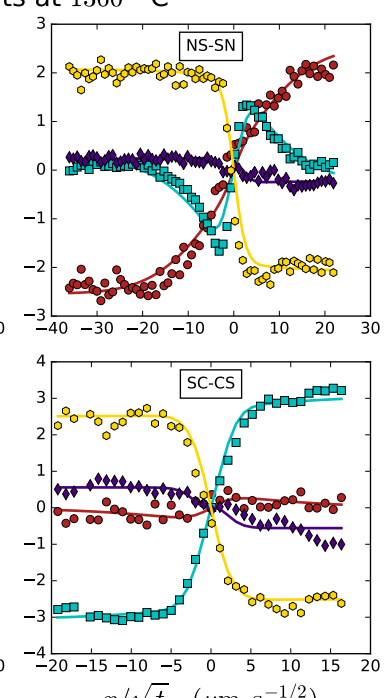

$x / \sqrt{t}\left(\mu \mathrm{m} \cdot \mathrm{s}^{-1 / 2}\right)$

Figure 4: Concentration profiles for all successful diffusion couples at $1360^{\circ} \mathrm{C}$, for 20 -min thermal treatments.

\begin{tabular}{c|c|c|c} 
& $\mathbf{v}_{1}$ & $\mathbf{v}_{2}$ & $\mathbf{v}_{3}$ \\
\hline $\mathrm{Na}_{2} \mathrm{O}$ & 1 & 0 & 0 \\
$\mathrm{CaO}$ & -1 & 1 & 1 \\
$\mathrm{Al}_{2} \mathrm{O}_{3}$ & 0 & 0 & -1 \\
$\mathrm{SiO}_{2}$ & 0 & -1 & 0 \\
\hline$\alpha_{i}^{1200}$ & 29.8 & 1.03 & 0.18 \\
\hline$\alpha_{i}^{1280}$ & 50.9 & 2.63 & 0.40 \\
\hline$\alpha_{i}^{1360}$ & 68.3 & 3.96 & 0.73
\end{tabular}

Table 7: Eigenvalues $\left(\times 10^{-12} \mathrm{~m}^{2} \cdot \mathrm{s}^{-1}\right)$ and eigenvectors obtained by imposing the direction of eigenvectors.

\section{Discussion}

\subsection{Direction of eigenvectors}

From the result of the fits at high temperature and close to $T_{g}$, it seems that at high temperature eigenvectors $\mathbf{v}_{2}$ and $\mathbf{v}_{3}$, involve both network formers. In particular $\mathbf{v}_{2}$ represents the exchange of calcium with silicon, and a smaller fraction of aluminum. However, close to $T_{g}$ eigenvectors involve only two species each, with $\mathbf{v}_{2}$ being simply the exchange of calcium and silicon. The question arises whether this evolution is due to a real physical change of melt structure and diffusion eigenvectors, or to experimental noise and fitting errors. To address this question, we have tried to fit high-temperature data with an imposed basis of eigenvectors, so that only eigenvalues remain to be fitted. We have chosen the basis $\mathbf{v}_{1}=(1,-1,0,0), \mathbf{v}_{2}={ }_{38}$ 


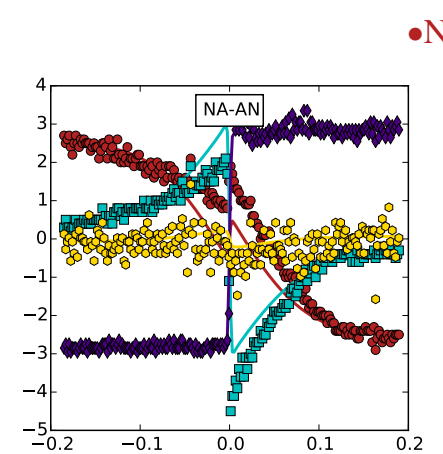

$-\mathrm{Na}_{2} \mathrm{O} \quad \mathrm{CaO} \diamond \mathrm{Al}_{2} \mathrm{O}_{3}$
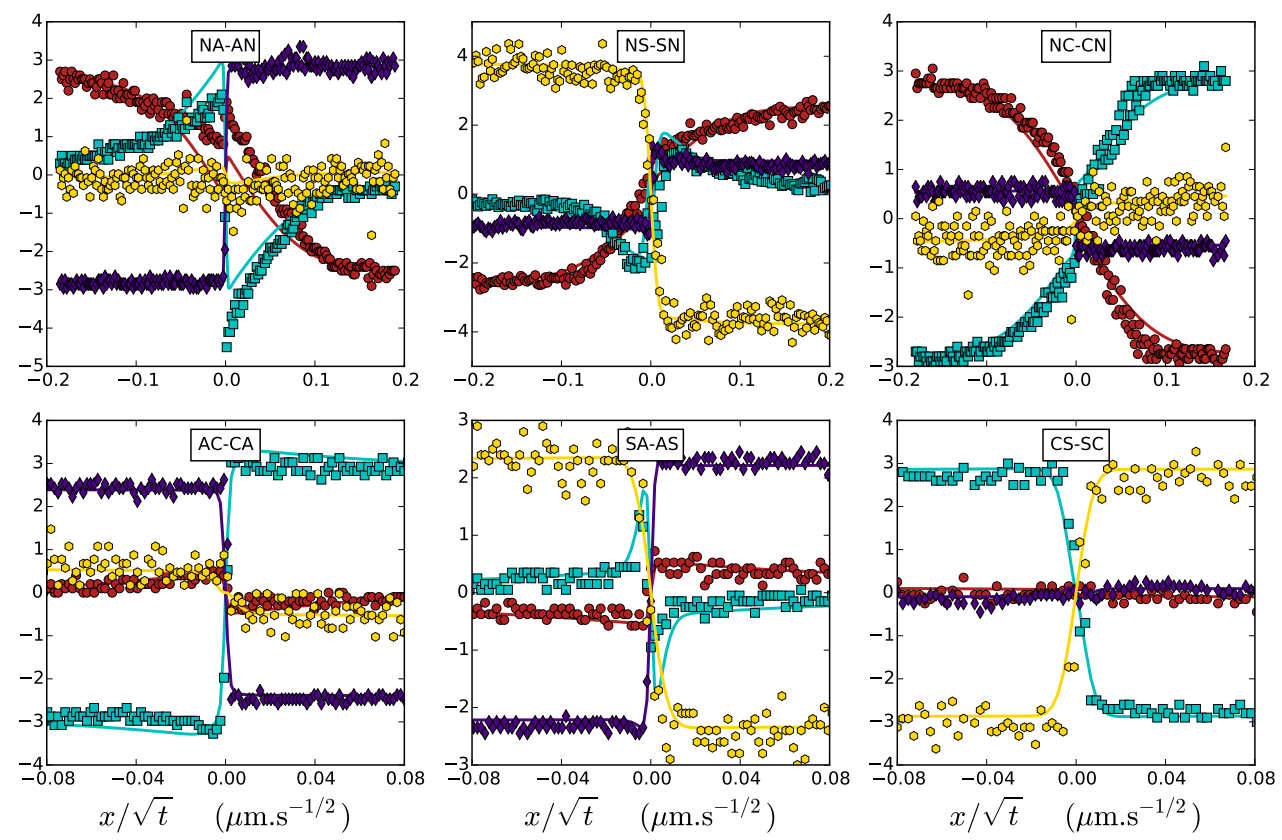

Figure 5: Concentration profiles for all diffusion couples close to the glass transition $\left(T_{g}+30\right)$.
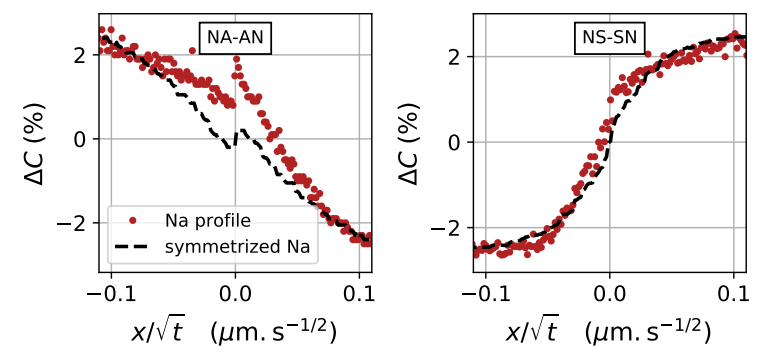

Figure 6: Concentration profiles of sodium (symbols) close to the glass transition for the NA-NA and NS-SN couples (close-up compared to Fig. 5), and symmetrized profiles (dotted lines). The difference between experimental and symmetrized profiles highlights the asymmetry of experimental profiles.
$(0,1,0,-1), \mathbf{v}_{3}=(0,1,-1,0)$ (see Table 7$)$, that is, the basis found close to $T_{g}$ if small coefficients are set to 0 .

We found that the fit is visually as good as when the eigenvectors are free to vary, with a value of the least-square error that is only slightly larger. Eigenvalues found with this basis are reported in Table 7. With the experimental uncertainty of our measurements, we think that it is not possible to conclude at this time, whether at high temperature $\mathbf{v}_{2}$ is the exchange of calcium with silicon only, or with silicon and aluminum.

In order to answer this question, either more data or more accurate data would be needed. One could perform diffusion experiments along different directions of the phase diagram, taking extra care to keep the sodium content equal for the endmembers. Indeed, since the dominant eigenvalue is much larger than the second one, $\mathbf{v}_{2}$ could be determined more accurately from experiments for which the contribution of $\mathbf{v}_{1}$ is strictly zero.

\subsection{Common basis of eigenvectors at superliquidus temperatures}

Since diffusion profiles obtained at different temperatures are very similar, and since the estimated direction of eigenvectors does not change much with temperature, we fitted the diffusion profiles at all high temperatures using a common basis of eigenvectors. Theoreti- 


\begin{tabular}{c|c|c|c} 
& $\mathbf{v}_{1}$ & $\mathbf{v}_{2}$ & $\mathbf{v}_{3}$ \\
\hline $\mathrm{Na}_{2} \mathrm{O}$ & 1 & 0.04 & 0.07 \\
$\mathrm{CaO}$ & -0.86 & 1 & -0.67 \\
$\mathrm{Al}_{2} \mathrm{O}_{3}$ & -0.01 & -0.34 & 1 \\
$\mathrm{SiO}_{2}$ & -0.13 & -0.71 & -0.40 \\
\hline$\alpha_{i}^{1200}$ & 32.7 & 0.52 & 0.11 \\
\hline$\alpha_{i}^{\alpha 280}$ & 52.5 & 1.37 & 0.31 \\
\hline$\alpha_{i}^{\alpha 360}$ & 91.4 & 4.58 & 0.77 \\
\hline$E_{a}\left(\mathrm{~kJ} \cdot \mathrm{mol}^{-1}\right)$ & 134 & 304 & 241
\end{tabular}

Table 8: Eigenvectors and eigenvalues $\left(\times 10^{-12} \mathrm{~m}^{2} \cdot \mathrm{s}^{-1}\right)$ obtained by fitting experimental data of the $[1200-1360]^{\circ} \mathrm{C}$ range in a common basis. Activation energies $\left(E_{a}\right)$ are obtained from an Arrhenian fit of eigenvalues. cally, the number of experiments at each temperature is greater than that (3) required to constrain the system of equations. However, due to experimental noise and the ill-conditioning of the diffusion matrices, increasing the number of experiments permits a more accurate estimation of eigenvectors and eigenvalues. We did not include the data close to the glass transition, since asymmetries of diffusion profiles introduce more errors in the fitting procedure. The result of the fitting procedure is shown in Table 8. The eigenvectors are closer to the ones obtained at $1200^{\circ} \mathrm{C}$, for which more experiments are available and the estimation is likely to be more accurate than for the other temperatures. In the following, we use the set of eigenvalues $\alpha_{i}^{*}$ determined with the common basis of eigenvectors, since they should be more accurate than eigenvalues obtained for one temperature only.

\subsection{Arrhenian behavior of eigenvalues}

Fig. 7 a) shows the eigenvalues $\alpha_{i}^{*}$ in an Arrhenian diagram, as a function of reciprocal temperature. Although three temperatures are the bare minimum to test for an Arrhenian behavior, experimental points are well aligned on an exponential curve. Activation energies fitted on the $[1200-1360]^{\circ} \mathrm{C}$ regime are reported in Table 8 .

The activation energy for the exchange of network modifiers is $134 \mathrm{~kJ}^{\mathrm{mol}}{ }^{-1}$. For comparison, (Gruener et al., 2001) found an activation energy of $\simeq$ $120 \mathrm{~kJ} . \mathrm{mol}^{-1}$ for the relaxation time of calcium in calcium aluminosilicate melts (which was measured by NMR at high temperature and by electrical conductivity closer to the glass transition). Activation energies for the mobility of sodium are typically smaller (e.g.

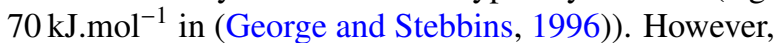
the exchange between sodium and calcium is likely to be controlled by calcium, which is the slowest species.
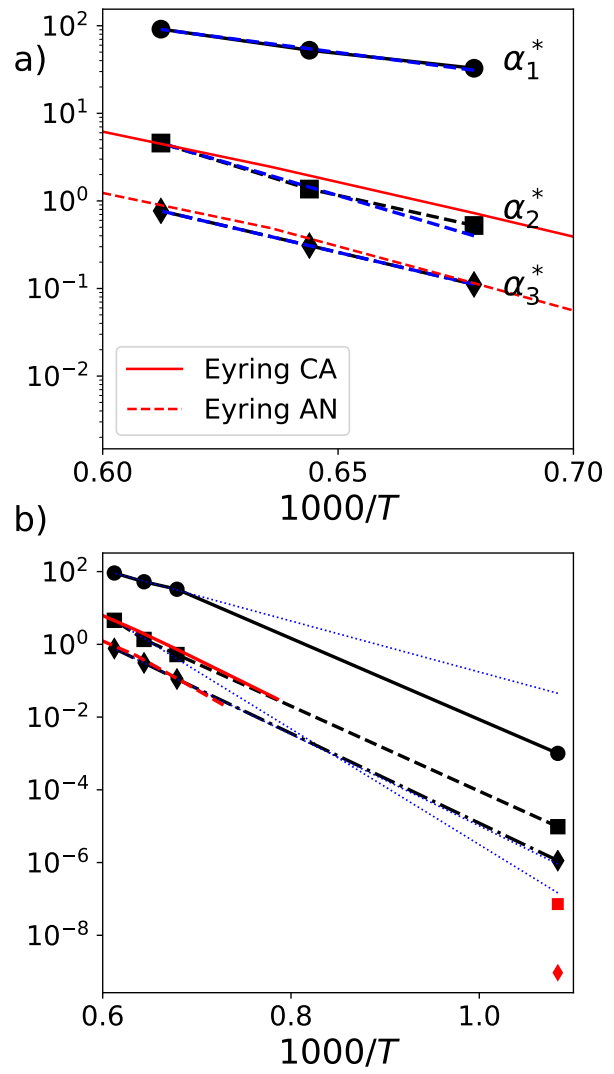

Figure 7: Arrhenian dependence of eigenvalues $\alpha_{i}^{*}$ with temperature. a) zoom on high temperatures only. b) high temperatures and $T_{g}+30$. Black symbols correspond to eigenvalues, blue lines (color online) to the Arrhenian fit of high-temperature eigenvalues, and red lines and red symbols to the Eyring diffusivities (see text). 
The activation energies of exchanges involving network formers are 304 and $241 \mathrm{~kJ}^{\mathrm{mol}}{ }^{-1}$, consistent with activation energies found for viscosity measurements. In order to test the link with viscosity further, we plotted in Fig. 7 a) the Eyring diffusivity estimated as

$$
D^{E}=\frac{k_{B} T}{\eta d}
$$

where $\eta$ is the melt viscosity and $d$ is a jump distance corresponding to a diffusive step. Following previous studies (Zhang et al., 2010; Lesher, 2010; Ni et al., 2015; Micoulaut, 2016), we choose $d=2.8 \AA$, the oxygen-oxygen interatomic distance in silicate melts. Since the different endmembers have different viscosities, we have reported in Fig. 7 Eyring diffusivities for the melt with the smallest (CA, an Al-poor composition) and largest ( $\mathrm{AN}$, an Al-rich composition) values of viscosities. Interestingly, in the $[1200-1360]^{\circ} \mathrm{C}$ range, $D_{C A}^{E}$ is close to $\alpha_{2}^{*}$, while $D_{A N}^{E}$ is close to $\alpha_{3}^{*}$. This observation is consistent with the fact that $\alpha_{2}^{*}$ characterizes the exchange of calcium with silicon (and some aluminum), while $\alpha_{3}^{*}$ characterizes the exchange of calcium with aluminum. This good correspondence between eigenvalues and viscosities is particularly interesting, and should be investigated in more systems in the future.

In Fig. 7 b), we added eigenvalues close to glass transition, as well as Eyring diffusivities (Eq. (4)) computed at $650^{\circ} \mathrm{C}$ for the $\mathrm{SN}$ and $\mathrm{NC}$ compositions (which have respectively the largest and smallest viscosities at $T_{g}+30$ except for the AN/NA experiment, for which the temperature was too different from the others). It is interesting to see that, contrary to superliquidus temperatures, Eyring diffusivities (red symbols) are significantly smaller than the eigenvalues $\alpha_{2}^{*}$ and $\alpha_{3}^{*}$. On the other hand, eigenvalues $\alpha_{2}^{*}$ and $\alpha_{3}^{*}$ close to $T_{g}$ seem to lie approximately on the same Arrhenian (exponential) curve as high-temperature eigenvalues. The (blue) dotted lines in Fig. 7 b) correspond to the Arrhenian extrapolation using the activation energy determined on the hightemperature eigenvalues. The red lines represent the Eyring diffusivities extrapolated using an Arrhenian fit for high-temperature values of $\eta_{\mathrm{CA}}$ and $\eta_{\mathrm{AN}} . \alpha_{2}^{*}$ and $\alpha_{3}^{*}$ close to $T_{g}$ are well approximated by the Arrhenian extrapolation of Eyring diffusivities to low temperatures. The Arrhenian extrapolation of high-temperature eigenvalues allows one to retrieve $\alpha_{3}^{*}\left(T_{g}\right)$, but is less accurate for $\alpha_{2}^{*}$. Since the gap between 650 and $1200^{\circ} \mathrm{C}$ is very large, small uncertainties in the fitted high-temperature activation energy will result in a large difference when the exponential curve is extended to $T_{g}$. However for the viscosities we have more values ( 6 values between
1000 and $1500^{\circ} \mathrm{C}$ ) to constrain the parameters of the Arrhenian law, resulting in more accuracy.

The breakdown of the Eyring relation has been studied in model numerical liquids (Kumar et al., 2006; Charbonneau et al., 2014) close to the glass transition. It has been attributed to a decoupling between relaxation mechanisms responsible for diffusion and viscous flow. In particular, the hopping of particles out of cages formed by their neighbors (Charbonneau et al., 2014) allows particles to diffuse even at temperatures at which viscous flow is much slower. Using the formalism of the Adam-Gibbs theory and configurational entropy, the fragility of silicate supercooled liquids is associated to an increasing number of units involved in structural relaxation when the glass transition is approached (Richet, 1984; Toplis, 1998). We suggest that, on the contrary, diffusion exchanges associated to eigenvalues remain a local process involving the break and reforming of a few chemical bonds (Claireaux et al., 2016), which could explain why their temperature dependence is Arrhenian over the whole temperature range studied here.

We are not aware of any other direct experimental study of diffusion in silicate supercooled liquids mentioning the breakdown of the Eyring relation. Several studies (Reinsch et al., 2008; Nascimento et al., 2011; Schmelzer et al., 2015) have shown that the energetics of crystal growth do not follow Eyring relation close to the glass transition, but the interpretation of the diffusivity coefficient in the law of crystal growth is still subject to debate (Cassar et al., 2018). NMR 2D MAS measures of the $Q_{3}-Q_{4}$ exchange rates showed that the Eyring relation was verified up to $55^{\circ} \mathrm{C}$ above the glass transition in $\mathrm{K}_{2} \mathrm{Si}_{4} \mathrm{O}_{9}$ liquids. However, in $1 \mathrm{D}$ NMR measurements some decoupling has been observed (Farnan and Stebbins, 1990; Stebbins et al., 1995) between exchanges rates and viscosity. Moreover, new techniques such as X-ray Photon Correlation Spectroscopy have evidenced in sodium silicate liquids (Ruta et al., 2014) relaxation mechanisms unknown so far close to the glass transition. Other multidiffusion studies close to the glass transition would be required to conclude about a possible breakdown of the Eyring relation.

\subsection{Multidiffusion effects close to the glass transition}

To the best of our knowledge, this work is the first evidence that multidiffusion effects, including uphill diffusion, are effective close to the glass transition. A recent study (Pablo et al., 2017) of multidiffusion in a sodium borosilicate system considered temperatures as low as 100 degrees above the glass transition. Viscosities of endmembers were of the order of $10^{8} \mathrm{~Pa} . \mathrm{s}$, while in our 
experiments $\eta$ is of the order of $10^{10} \mathrm{~Pa}$.s, and varies between $10^{8.8}$ and $10^{11}$ Pa.s.

The assumption of a constant diffusion matrix is less valid than at higher temperature, because of higher viscosity difference for a given concentration difference. Nevertheless, the measured diffusion eigenvectors are very similar to higher temperatures, meaning that the same exchange mechanisms are valid over a wide temperature range. The fact that only two species are involved in each diffusion eigenvector near $T_{g}$ means that even when thermal agitation is less effective, cooperative rearrangements can still happen. A difference between high temperature and close to $T_{g}$ is the stronger influence of aluminum gradients on sodium flux, close to the glass transition. This stronger influence can be read directly in the $D_{N a, A l}$ coefficient of the diffusion matrix in Table 5. With $D_{N a, A l}=-6.4 \cdot 10^{-16}$ and $D_{N a, N a}=11.9 \cdot 10^{-16} \mathrm{~m}^{2} . \mathrm{s}^{-1}$ close to $T_{g}$, an aluminum gradient creates a sodium flux whose magnitude is half that of the flux created by its own (sodium) gradient. The relative magnitude of $D_{N a, A l}$ is much lower at higher temperatures, with for example $D_{N a, A l}=-5 \cdot 10^{-12}$ and $D_{N a, N a}=29 \cdot 10^{-12} \mathrm{~m}^{2} \cdot \mathrm{s}^{-1}$ at $1200^{\circ} \mathrm{C}$. This difference is probably due to the competition between sodium and calcium as charge compensators of aluminum. Calorimetry measurements at $985 \mathrm{~K}$ (Navrotsky et al., 1982), and more recently NMR experiments on quenched glasses of the NCAS system (Gambuzzi et al., 2014, 2015) revealed that aluminum tetrahedra are preferentially compensated by sodium ions. Aluminumrich compositions have barely enough sodium to compensate all aluminum tetrahedra (or not enough for the AN/NA experiment), meaning that a fraction of tetrahedra are compensated by calcium ions. When put in contact with an aluminum-poor composition, sodium network modifiers diffuse to the aluminum-rich part to compensate more aluminum tetraehdra, resulting in the slight uphill diffusion of sodium observed for the experiments with an aluminum gradient. The study of (Gambuzzi et al., 2014, 2015) was performed on quenched glasses, and should therefore be representative of the supercooled liquid structure close to the glass transition. We are not aware of a similar structural study of NCAS glasses at high temperature. For the high temperatures, the much weaker coupling between sodium and aluminum probably means that a better random mixing between sodium and calcium charge compensators is favored by entropy at high temperature. Therefore, information about melt and supercooled liquid structures can be gained from multidiffusion analysis, even if the exact structure of the liquid is lost upon quenching.
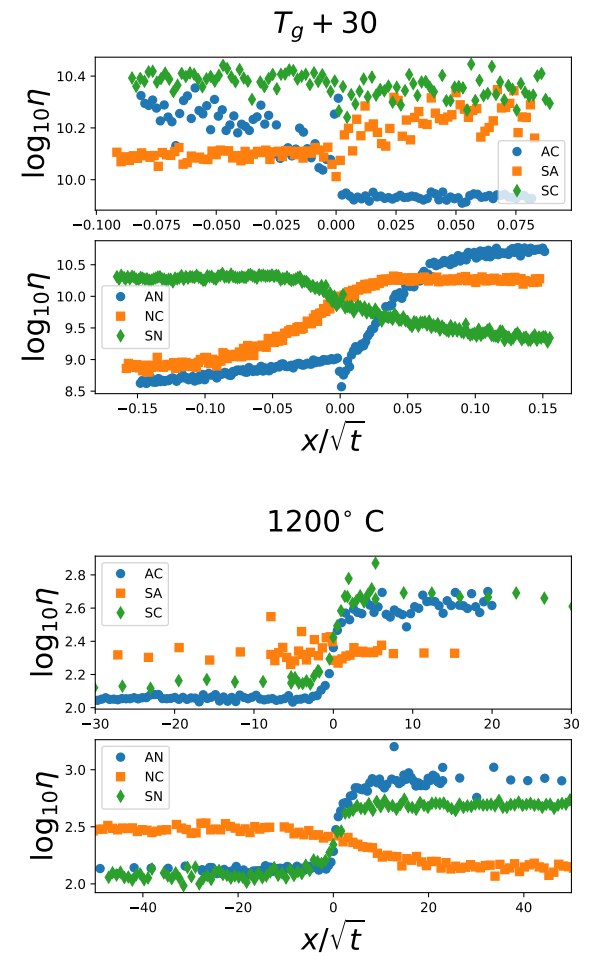

Figure 8: Viscosities along diffusion profiles, interpolated between end-member viscosities (see text), at $T_{g}+30 \mathrm{a}$ ) and $1200^{\circ} \mathrm{C} \mathrm{b}$ ). For easier visualization, we have separated in two subplots experiments with and without significant sodium gradient.

\subsection{Viscosity gradients and their effect of diffusion}

While viscosities of endmembers can be computed for the different temperatures using the VFT law of Fig 1, it is also interesting to know how viscosity varies along a given diffusion profile. To this end, we used the parametric dependence on composition proposed by (Giordano et al., 2008) and we determined the parameters of the model using a least-square fit on the 120 measured viscosities ( 24 close to $T_{g}$ and 96 at high temperature). With this model it is possible to compute an estimation of the viscosity for every composition along a given diffusion profile in our composition range. Resulting viscosity profiles are shown in Fig. 8 for $T_{g}+30$ and $1200^{\circ} \mathrm{C}$. For both temperatures, the largest viscosity gradients involve the exchange of sodium with another species. Viscosity profiles evolve monotonically, that is, no uphill shape is observed even for the profiles corresponding to non-straight trajectories in composition space. The only exception is the interface of the AN/NA profile at $T_{g}+30$, where the slight discontinuity is probably due to the uphill diffusion of sodium as described above. 


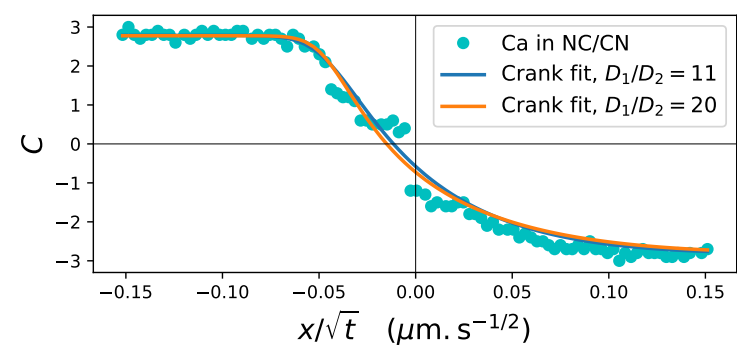

Figure 9: Ca profile for the $\mathrm{NC} / \mathrm{CN}$ exchange at $T_{g}+30$, fitted using the concentration-dependent viscosity of Crank (Crank, 1979). The best least-square fit corresponds to a ratio of diffusivities of 11 between endmembers, while the ratio of 20 is the estimated ratio of viscosities between endmembers. .

Strong viscosity variations are likely to change the intensity of diffusion across a diffusion profile, i.e. the magnitude of eigenvalues. Indeed, the variation of eigenvalues is reflected in the asymmetry of diffusion profiles in Fig. 5. One could parametrize the diffusion matrix or its eigenvalues as a function of viscosity using Eyring relation, but it would lead to a system of partial differential equations which would involve significant computational effort. Alternatively, a classical model for concentration-dependent diffusion is the model of Crank (Crank, 1979), where (scalar) diffusion depends exponentially on concentration

$$
D(C)=D_{0} \exp \left(\beta\left(C-\frac{1}{2}\left(C_{1}+C_{2}\right)\right)\right),
$$

where $C_{1}$ and $C_{2}$ are the initial concentrations of endmembers and $\beta$ is the strength of dependence on concentration. This equation is consistent with Eyring relation, since viscosity has an exponential dependence with concentration (Giordano et al., 2008). The extension of Eq. (5) to the case of multidiffusion is technically challenging and out of the scope of this article. In addition, the spatial resolution of our measurements is not enough to identify asymmetries in the profile of network formers, so that only the profiles of network modifiers can be studied using the model of Crank.

As an illustration, we have fitted the calcium profile of the NC/CN exchange at $T_{g}+30$, using Eq. (5) (see Fig. 9). Since the direction of this exchange corresponds to an eigenvector, effective binary diffusion models correctly this exchange, and it is valid to fit the profile using a model for scalar diffusion. Fig. 9 shows that Crank's model is able to account for the shape of the diffusion profile. The best fit parameters correspond to a ratio of diffusivity of 11 between the endmembers. Interestingly, the ratio of viscosity between the $\mathrm{NC}$ and $\mathrm{CN}$ compositions is of the order of 20 (see Fig. 8 (a)), a comparable order of magnitude. In Fig. 9, we also show the theoretical profile for a ratio of 20 , and the best fit value of $D_{0}$ in Eq. (5): the agreement is also very good.

Therefore, the eigenvalues fitted close to $T_{g}$ using a constant diffusion matrix correspond to intermediate values between exchange rates in compositions with largest and smallest viscosities. Our choice not to use the AN/NA data close to the $T_{g}$ for computing the diffusion matrix reduces the incertitude on eigenvalues, since the viscosity contrast is almost one order of magnitude larger than for all the other experiments. The smaller viscosity contrast between endmembers at $1200^{\circ} \mathrm{C}$ and above mean that the effect of viscosity on eigenvalues can be neglected.

Finally, it is interesting to note that the diffusion couples that are most prone to convection correspond to the largest difference of viscosity between the two endmembers, with AN/NA the most problematic couple and the largest viscosity difference. It is known that viscositystratified fluids can give rise to flow instabilities (Govindarajan and Sahu, 2014) and affect the onset and wavelengths of thermal convection (Zhang and Yuen, 1995; Bunge and Richards, 1996; Ratcliff et al., 1997). More insights into the effect of viscosity stratification would help to reduce convection in future experiments.

\section{Conclusion}

Using diffusion-couple experiments and several variants of least-square optimization, we have determined diffusion matrices for a region of composition centered on $64.5 \mathrm{wt} \% \mathrm{SiO}_{2}, 13.3 \mathrm{wt} \% \mathrm{Na}_{2} \mathrm{O}, 10.8 \mathrm{wt} \% \mathrm{CaO}, 11.4$ $\mathrm{wt} \% \mathrm{Al}_{2} \mathrm{O}_{3}$. Diffusion matrices have been obtained for several super-liquidus temperatures, as well as $30 \mathrm{de}-$ grees above the glass transition. Diffusion matrices have been interpreted using their eigenvalues and eigenvectors. A remarkable persistence of eigenvector directions was found through this temperature range, with the dominant eigenvector representing the exchange of sodium with calcium and the two other eigenvectors representing the exchange of calcium with network formers. The activation energy of the dominant eigenvector is consistent with that of electrical conductivity. At high temperature, good quantitative agreement was found between Eyring diffusivities and eigenvalues for exchanges with network formers, when using the extreme viscosity values reached over the composition domain in the Eyring formula. Close to the glass transition, Eyring relation did not seem to apply, with diffusion exchanges involving network formers being faster 


\section{References}

Acosta-Vigil, A., London, D., Dewers, T. A., Morgan, G. B., 2002 Dissolution of corundum and andalusite in $\mathrm{H}_{2} \mathrm{O}$-saturated haplogranitic melts at $800^{\circ} \mathrm{C}$ and $200 \mathrm{MPa}$ : constraints on diffusivities and the generation of peraluminous melts. Journal of Petrology 43 (10), 1885-1908.

Acosta-Vigil, A., London, D., Morgan, G. B., Dewers, T. A., 2006. Dissolution of quartz, albite, and orthoclase in $\mathrm{H}_{2} \mathrm{O}$-saturated haplogranitic melt at $800^{\circ} \mathrm{C}$ and $200 \mathrm{MPa}$ : Diffusive transport properties of granitic melts at crustal anatectic conditions. Journal of Petrology 47 (2), 231-254.

Aniya, M., 1992. A chemical approach for the microscopic mechanism of fast ion transport in solids. Solid State Ionics 50 (1-2), 125-129.

Bottinga, Y., Weill, D., Richet, P., 1982. Density calculations for silicate liquids. i. revised method for aluminosilicate compositions. Geochimica et Cosmochimica Acta 46 (6), 909-919.

Bouttes, D., Lambert, O., Claireaux, C., Woelffel, W., Dalmas, D., Gouillart, E., Lhuissier, P., Salvo, L., Boller, E., Vandembroucq, D., 2015. Hydrodynamic coarsening in phase-separated silicate melts. Acta Materialia 92, 233-242.

Bunge, H.-P., Richards, M. A., 1996. The origin of large scale structure in mantle convection: effects of plate motions and viscosity stratification. Geophysical Research Letters 23 (21), 2987-2990.

Cassar, D. R., Rodrigues, A. M., Nascimento, M. L. F., Zanotto, E. D., 2018. The diffusion coefficient controlling crystal growth in a silicate glass-former. International Journal of Applied Glass Science 9 (3), 373-382.

Chakraborty, S., Dingwell, D. B., Rubie, D. C., 1995. Multicomponent diffusion in ternary silicate melts in the system $\mathrm{K}_{2} \mathrm{O}-\mathrm{Al}_{2} \mathrm{O}_{3}-\mathrm{SiO}_{2}$ : II. mechanisms, systematics, and geological applications. Geochimica et Cosmochimica Acta 59 (2), 265-277.

Charbonneau, P., Jin, Y., Parisi, G., Zamponi, F., 2014. Hopping and the stokes-einstein relation breakdown in simple glass formers. Proceedings of the National Academy of Sciences 111 (42), 15025-15030.

Chen, Y., Zhang, Y., 2008. Olivine dissolution in basaltic melt. Geochimica et Cosmochimica Acta 72 (19), 4756-4777.

Claireaux, C., Chopinet, M.-H., Burov, E., Gouillart, E., Roskosz, M., Toplis, M. J., 2016. Atomic mobility in calcium and sodium aluminosilicate melts at $1200^{\circ} \mathrm{c}$. Geochimica et Cosmochimica Acta 192, 235-247.

Crank, J., 1979. The mathematics of diffusion. Oxford university press.
Edwards, B., Russell, J., 1996. A review and analysis of silicate mineral dissolution experiments in natural silicate melts. Chemical Geology 130 (3), 233-245.

Farnan, I., Stebbins, J., 1990. High-temperature silicon-29 nmr investigation of solid and molten silicates. Journal of the American Chemical Society 112 (1), 32-39.

Fluegel, A., Earl, D. A., Varshneya, A. K., Seward, T. P., 2008. Density and thermal expansion calculation of silicate glass melts from 1000 c to 1400 c. Physics and Chemistry of Glasses-European Journal of Glass Science and Technology Part B 49 (5), 245-257.

Fonné, J.-T., Burov, E., Gouillart, E., Grachev, S., Hervé, M., 2017. Aluminum-enhanced alkali diffusion from float glass to pvdsputtered silica thin films. Journal of the American Ceramic Society.

Gambuzzi, E., Charpentier, T., Menziani, M. C., Pedone, A., 2014. Computational interpretation of 23 na mqmas nmr spectra: a comprehensive investigation of the na environment in silicate glasses. Chemical Physics Letters 612, 56-61.

Gambuzzi, E., Pedone, A., Menziani, M. C., Angeli, F., Florian, P., Charpentier, T., 2015. Calcium environment in silicate and aluminosilicate glasses probed by 43 ca mqmas $\mathrm{nmr}$ experiments and md-gipaw calculations. Solid state nuclear magnetic resonance 68 , 31-36.

George, A., Stebbins, J., 1996. Dynamics of na in sodium aluminosilicate glasses and liquids. Physics and Chemistry of Minerals 23 (8), 526-534.

Giordano, D., Russell, J. K., Dingwell, D. B., 2008. Viscosity of magmatic liquids: a model. Earth and Planetary Science Letters 271 (1), 123-134

Govindarajan, R., Sahu, K. C., 2014. Instabilities in viscositystratified flow. Annual Review of Fluid Mechanics 46, 331-353.

Gruener, G., Odier, P., Meneses, D. D. S., Florian, P., Richet, P., 2001. Bulk and local dynamics in glass-forming liquids: a viscosity, electrical conductivity, and nmr study of aluminosilicate melts. Physical Review B 64 (2), 024206.

Hull, S., 2004. Superionics: crystal structures and conduction processes. Reports on Progress in Physics 67 (7), 1233.

Jain, H., Peterson, N. L., Downing, H., 1983. Tracer diffusion and electrical conductivity in sodium-cesium silicate glasses. Journal of Non-Crystalline Solids 55 (2), 283-300.

Jambon, A., 1982. Tracer diffusion in granitic melts: experimental results for $\mathrm{Na}, \mathrm{K}, \mathrm{Rb}, \mathrm{Cs}, \mathrm{Ca}, \mathrm{Sr}, \mathrm{Ba}, \mathrm{Ce}, \mathrm{Eu}$ to $1300^{\circ} \mathrm{C}$ and a model of calculation. Journal of Geophysical Research: Solid Earth (1978-2012) 87 (B13), 10797-10810.

Jund, P., Kob, W., Jullien, R., 2001. Channel diffusion of sodium in a silicate glass. Physical Review B 64 (13), 134303.

Kumar, S. K., Szamel, G., Douglas, J. F., 2006. Nature of the breakdown in the stokes-einstein relationship in a hard sphere fluid. The Journal of chemical physics 124 (21), 214501.

Lesher, C. E., 2010. Self-diffusion in silicate melts: theory, observations and applications to magmatic systems. Reviews in Mineralogy and Geochemistry 72 (1), 269-309.

Liang, Y., 1999. Diffusive dissolution in ternary systems: analysis with applications to quartz and quartzite dissolution in molten silicates. Geochimica et Cosmochimica Acta 63 (23), 3983-3995.

Liang, Y., 2010. Multicomponent diffusion in molten silicates: theory, experiments, and geological applications. Reviews in Mineralogy and Geochemistry 72 (1), 409-446.

Liang, Y., Davis, A. M., 2002. Energetics of multicomponent diffusion in molten $\mathrm{CaO}-\mathrm{Al}_{2} \mathrm{O}_{3}-\mathrm{SiO}_{2}$. Geochimica et cosmochimica acta $66(4), 635-646$.

Mazurin, O., Streltsina, M., 1972. Determination of tie-line directions in the metastable phase-separation regions of ternary systems. Journal of Non-Crystalline Solids 11 (3), 199-218.

Meyer, A., Horbach, J., Kob, W., Kargl, F., Schober, H., 2004. Chan- 
nel formation and intermediate range order in sodium silicate melts and glasses. Physical review letters 93 (2), 027801.

Micoulaut, M., 2016. Relaxation and physical aging in network glasses: a review. Reports on Progress in Physics 79 (6), 066504.

Mungall, J. E., Romano, C., Dingwell, D. B., 1998. Multicomponent diffusion in the molten system $\mathrm{K}_{2} \mathrm{O}-\mathrm{Na}_{2} \mathrm{O}-\mathrm{Al}_{2} \mathrm{O}_{3}-\mathrm{SiO}_{2}-\mathrm{H}_{2} \mathrm{O}$. American Mineralogist 83 (7), 685-699.

Nascimento, M. L. F., Ferreira, E. B., Zanotto, E. D., 2004. Kinetics and mechanisms of crystal growth and diffusion in a glass-forming liquid. The Journal of chemical physics 121 (18), 8924-8928.

Nascimento, M. L. F., Fokin, V. M., Zanotto, E. D., Abyzov, A. S., 2011. Dynamic processes in a silicate liquid from above melting to below the glass transition. The Journal of chemical physics 135 (19), 194703.

Natrup, F., Bracht, H., Murugavel, S., Roling, B., 2005. Cation diffusion and ionic conductivity in soda-lime silicate glasses. Physical chemistry chemical physics 7 (11), 2279-2286.

Navrotsky, A., Peraudeau, G., McMillan, P., Coutures, J.-P., 1982. A thermochemical study of glasses and crystals along the joins silica-calcium aluminate and silica-sodium aluminate. Geochimica et Cosmochimica Acta 46 (11), 2039-2047.

Ni, H., Hui, H., Steinle-Neumann, G., 2015. Transport properties of silicate melts. Reviews of Geophysics.

Pablo, H., Schuller, S., Toplis, M., Gouillart, E., Mostefaoui, S., Charpentier, T., Roskosz, M., 2017. Multicomponent diffusion in sodium borosilicate glasses. Journal of Non-Crystalline Solids.

Priven, A., 2004. General method for calculating the properties of oxide glasses and glass forming melts from their composition and temperature. Glass Technology-European Journal of Glass Science and Technology Part A 45 (6), 244-254.

Ratcliff, J. T., Tackley, P. J., Schubert, G., Zebib, A., 1997. Transitions in thermal convection with strongly variable viscosity. Physics of the earth and planetary interiors 102 (3-4), 201-212.

Reinsch, S., Nascimento, M. L. F., Müller, R., Zanotto, E. D., 2008. Crystal growth kinetics in cordierite and diopside glasses in wide temperature ranges. Journal of Non-Crystalline Solids 354 (52-54), 5386-5394.

Richet, P., 1984. Viscosity and configurational entropy of silicate melts. Geochimica et Cosmochimica Acta 48 (3), 471-483.

Roselieb, K., Jambon, A., 1997. Tracer diffusion of potassium, rubidium, and cesium in a supercooled jadeite melt. Geochimica et cosmochimica acta 61 (15), 3101-3110.

Roselieb, K., Jambon, A., 2002. Tracer diffusion of mg, ca, sr, and ba in na-aluminosilicate melts. Geochimica et cosmochimica acta 66 (1), 109-123.

Roskosz, M., Toplis, M. J., Richet, P., 2005. Experimental determination of crystal growth rates in highly supercooled aluminosilicate liquids: Implications for rate-controlling processes. American Mineralogist 90 (7), 1146-1156.

Roskosz, M., Toplis, M. J., Richet, P., 2006. Kinetic vs. thermodynamic control of crystal nucleation and growth in molten silicates. Journal of non-crystalline solids 352 (2), 180-184.

Ruta, B., Baldi, G., Chushkin, Y., Rufflé, B., Cristofolini, L., Fontana, A., Zanatta, M., Nazzani, F., 2014. Revealing the fast atomic motion of network glasses. Nature communications 5, 3939.

Schmelzer, J. W., Abyzov, A. S., Fokin, V. M., Schick, C., Zanotto, E. D., 2015. Crystallization in glass-forming liquids: Effects of decoupling of diffusion and viscosity on crystal growth. Journal of Non-Crystalline Solids 429, 45-53.

Smedskjaer, M. M., Zheng, Q., Mauro, J. C., Potuzak, M., Mørup, S., Yue, Y., 2011. Sodium diffusion in boroaluminosilicate glasses. Journal of Non-Crystalline Solids 357 (22), 3744-3750.

Spera, F. J., 2000. Physical properties of magma. Encyclopedia of volcanoes, 171-190.

Stebbins, J., Sen, S., Farnan, I., 1995. Silicate species exchange, viscosity, and crystallization in a low-silica melt: In situ hightemperature MAS NMR spectroscopy. American Mineralogist 80 (7), 861-864.

Tilocca, A., 2010. Sodium migration pathways in multicomponent silicate glasses: Car-Parrinello molecular dynamics simulations. The Journal of chemical physics 133 (1), 014701.

Toplis, M. J., 1998. Energy barriers to viscous flow and the prediction of glass transition temperatures of molten silicates. American Mineralogist 83 (5-6), 480-490.

Toplis, M. J., Gottsmann, J., Knoche, R., Dingwell, D. B., 2001. Heat capacities of haplogranitic glasses and liquids. Geochimica et Cosmochimica Acta 65 (12), 1985-1994.

Trial, A. F., Spera, F. J., 1994. Measuring the multicomponent diffusion matrix: Experimental design and data analysis for silicate melts. Geochimica et Cosmochimica Acta 58 (18), 3769-3783.

Vargheese, K. D., Tandia, A., Mauro, J. C., 2014. Molecular dynamics simulations of ion-exchanged glass. Journal of Non-Crystalline Solids 403, 107-112.

Zhang, S., Yuen, D. A., 1995. The influences of lower mantle viscosity stratification on 3d spherical-shell mantle convection. Earth and Planetary Science Letters 132 (1-4), 157-166.

Zhang, Y., Ni, H., Chen, Y., 2010. Diffusion data in silicate melts. Reviews in Mineralogy and Geochemistry 72 (1), 311-408. 